\title{
Assessment of the morphometry of heads of normal sperm and sperm with the Dag defect in the semen of Duroc boars
}

\author{
Dorota Banaszewska ${ }^{\varpi}$, Katarzyna Andraszek \\ Institute of Animal Science and Fisheries, Siedlce University of Natural Sciences and Humanities, 08-110 Siedlce, Poland \\ dorota.banaszewska@uph.edu.pl
}

Received:June 24, $2020 \quad$ Accepted: March 23, 2021

\begin{abstract}
Introduction: The Dag defect is one of the primary morphological defects in sperm correlating with reduced fertility. This defect is found in the spermatozoa of many livestock species. The aim of the study was to assess the morphometry of the heads of normal sperm and sperm with the Dag defect in the semen of Duroc breeding boars. Material and Methods: Sperm morphology was examined in ten ejaculates each from 12 Duroc boars. In total, 3,600 morphologically normal sperm and 838 sperm with the Dag defect were evaluated. The area, perimeter, length and width of the sperm head were measured and these basic morphometric parameters were used to calculate four additional shape indices characterising the sperm head, i.e. ellipticity, elongation, roughness and regularity. Results: Sperm with this defect had markedly smaller heads, $0.32 \mu \mathrm{m}$ shorter and $0.19 \mu \mathrm{m}$ narrower than the heads of sperm with normal morphological structure. The heads of sperm with the Dag defect also had a $1.1 \mu \mathrm{m}$ smaller perimeter and a $2.5 \mu \mathrm{m}^{2}$ smaller surface area than the heads of morphologically normal sperm. Conclusions: The Dag defect is found in boar sperm irrespective of the age of the individual. It affects the morphology of the sperm head.
\end{abstract}

Keywords: boar, Dag defect, morphometry, sperm, tail of spermatozoon.

\section{Introduction}

Abnormal sperm morphology has long been the subject of research by many authors, as in many cases it is a significant factor limiting male fertility. Abnormal morphology can not only reduce the fertilising capacity of sperm, but also affect the development and maintenance of pregnancy $(21,34)$. Some sperm anomalies that have already been classified may have a genetic basis. These include the Dag defect, first discovered in Jersey bulls.

Sperm with the Dag defect have circular, coiled tails, which is caused by the loss of some of the axial fibres of the tail. The typical arrangement of the tail fibres is disturbed within the coil and is characterised by the lack of 3-5 of them, which are located outside the tail but still within the cell membrane. This defect, referred to in the literature as 'tight coiling', 'tightly coiled Dag' or a 'Dag-like defect', besides coiling present as pronounced folding and fracture of the distal part of the sperm midpiece, sometimes with a distal cytoplasmic droplet (7). Oettlé (30) indicated that sperm with the Dag defect may have a tail coiled to varying degrees without an intact plasma membrane. These coils can be very loose or very tight, or the tail can even surround the sperm head (30). Abnormal axonemes are also typical of this defect. They are recognised by the loss of fibrils and the presence of loose fibrils within the cytoplasmic material (30). The Dag defect is very common in the spermatozoa of bulls, with more than $65 \%$ showing this defect in an Indian investigation (37). The authors of that research also found acrosome abnormalities in over $75 \%$ of sperm cells, which may confirm the genetic basis of both these types of abnormality. This defect is inherited due to an autosomal recessive factor and arises in the distal part of the epididymal caput (7). Ribeiro and Vale (33) suggest that inbreeding significantly determines the occurrence of this defect in buffalo sperm.

As the Dag defect probably has a genetic basis, and there has as yet been relatively little research on this subject, it is worth considering whether sperm with this anomaly have normal head morphometry. Domestic pigs are a species in which artificial insemination is used intensively. When young breeders are diagnosed early, losses can be limited by replacing a boar with poor 
reproductive performance and ascertained reduced sperm quality with another male, as boars with fertility problems in a nucleus herd can reduce litter sizes (29). Therefore, the aim of the study was to assess the morphometry of the heads of normal sperm and sperm with the Dag defect in the semen of Duroc breeding boars.

\section{Material and Methods}

The study was carried out in strict compliance with the recommendations in Directive 63/2010/EU on the protection of animals used for scientific or educational purposes and was approved by the Polish Second Local Ethics Committee in Warsaw (number 51/2015). The study was carried out on 12 Duroc boars used at an animal insemination station. The average age of the animals on the day of sample collection was $310.66 \pm 29.94$ days and the boars were in the age range of 7 to 26 months. For the first 1.5 years of use, an ejaculate sample was collected each month from each boar to examine sperm morphology. Ten ejaculates were obtained for analysis from each boar manually at about 6 a.m. The semen was kept at room temperature until examination of morphometry, for which it was prepared on slides within 15-20 min of collection. The eosin and gentian violet staining method was used, and smears were prepared for it by carefully dragging a drop of fresh semen across a degreased microscope slide heated to $37^{\circ} \mathrm{C}(25)$. The slides were allowed to air dry for a minimum of $2 \mathrm{~h}$, and were then preserved in a $96 \%$ ethanol solution for $5 \mathrm{~min}$ and then stained with a $10 \%$ aqueous solution of eosin for 20-60 s. The stained slides were washed in distilled water and stained with gentian violet for 3-5 min, after which they were gently rinsed with distilled water for 2 min to remove debris and then dried. This ensured a clean background, and thus a good contrast against the stained spermatozoa. All reagents used were purchased from Sigma-Aldrich Chemie (Taufkirchen, Germany). Morphometric assessment was performed for 30 wellformed sperm per slide (Fig. 1A) showing no visible defects and all sperm diagnosed with the Dag defect (Fig. 1B).

In total, 3,600 morphologically normal sperm and 838 sperm with the Dag defect were evaluated. The area, perimeter, length and width of the sperm head were measured, and these basic morphometric parameters were used to calculate four additional shape indices characterising the sperm head, i.e. ellipticity, elongation, roughness and regularity using the formulae given in Table 1 .

These parameters more precisely characterise the shape of the sperm head. Evaluations of morphometric measurements of the sperm head were performed using the MultiScan image analysis system for information extraction from slide photographs (Computer Scanning Systems, Warsaw, Poland) connected to an Olympus BX50 light microscope (Tokyo, Japan) at $1000 \times$ magnification through a $100 \times$ oil immersion objective and a Jenoptik ProgRes camera (Jena, Germany).

The morphometric measurements of the spermatozoa were stored in a database and exported for further statistical analysis. Statistical differences between the samples were tested using Tukey's test (Statistica version 10.0, StatSoft Inc., Tulsa, OK, USA) and the level of significance was set at $\mathrm{P} \leq 0.05$.

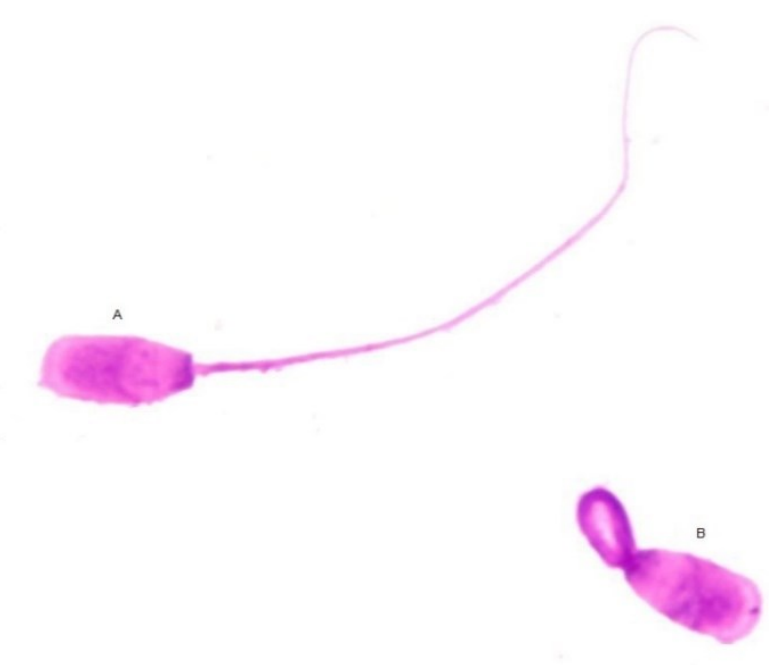

Fig. 1. Sperm with normal structure (A) and sperm with the Dag defect (B)

Table 1. Formulae used to calculate sperm head morphometric measurements

\begin{tabular}{ll}
\hline Variable & Formula \\
\hline Head length $(\mu \mathrm{m})$ & $\mathrm{L}$ \\
Head width $(\mu \mathrm{m})$ & $\mathrm{W}$ \\
Head perimeter $(\mu \mathrm{m})$ & $\mathrm{P}$ \\
Head area $\left(\mu \mathrm{m}^{2}\right)$ & $\mathrm{A}$ \\
Head ellipticity & $\mathrm{L} / \mathrm{W}$ \\
Head elongation & $(\mathrm{L}-\mathrm{W}) /(\mathrm{L}+\mathrm{W})$ \\
Head roughness & $4 \pi\left(\mathrm{A} / \mathrm{P}^{2}\right)$ \\
Head regularity & $\pi(\mathrm{L} \times \mathrm{W} / 4 \times \mathrm{A})$ \\
\hline
\end{tabular}

\section{Results}

Fig. 2 shows the changes in the frequency of sperm with the Dag defect in the semen of the Duroc boars. The data indicate that defective sperm are found in the semen of boars irrespective of their age. In the semen of young males just beginning to be used for breeding, the incidence of sperm with the Dag defect did not exceed $0.2 \%$. An increase in the incidence of sperm with this defect was observed in the semen of older boars aged 17-18 and 21-22 months. However, the percentage of sperm with the Dag defect did not exceed $0.42 \%$ at any age.

Table 2 presents the morphometric dimensions of the heads of sperm with normal morphological structure and sperm with the Dag defect. Sperm with this defect 
had markedly smaller heads. The heads of such sperm were $0.32 \mu \mathrm{m}$ shorter and $0.19 \mu \mathrm{m}$ narrower than the heads of sperm with normal tails $(\mathrm{P} \leq 0.05)$. The heads of sperm with the Dag defect also had a $1.1 \mu \mathrm{m}$ smaller perimeter and a $2.5 \mu \mathrm{m}^{2}$ smaller surface area than the heads of morphologically normal sperm $(\mathrm{P} \leq 0.05)$.

Table 3 presents indices that derive from the standard sperm head dimensions (length, width, perimeter and surface area) to which Tygerberg strict criteria were applied for a more precise analysis of the shape of the sperm head. The data indicate that the heads of sperm with normal structure had a lower ellipticity index than the heads of sperm with the Dag defect. Ellipticity indicates the degree to which the sperm heads are oval, narrow or conical. There were no differences in elongation, which indicates the roundness of the sperm head. Roughness, which specifies the regularity or amorphous shape of the sperm head, was higher for the heads of sperm with the Dag defect than for the heads of normal sperm $(\mathrm{P} \leq 0.05)$. Regularity indicates the symmetry of the sperm head and the degree to which it is pyriform. The regularity index was 0.02 higher for the heads of sperm with the Dag defect than for the heads of normal sperm $(\mathrm{P} \leq 0.05)$.
Table 2. Morphometric parameters of boar sperm measured manually with MultiScan software

\begin{tabular}{lll}
\hline $\begin{array}{l}\text { Morphometric } \\
\text { parameter }\end{array}$ & $\begin{array}{l}\text { Sperm with normal } \\
\text { structure }\end{array}$ & $\begin{array}{l}\text { Sperm with Dag } \\
\text { defect }\end{array}$ \\
\hline Head length $(\mu \mathrm{m})$ & $8.29^{\mathrm{a}} \pm 0.33$ & $7.97^{\mathrm{b}} \pm 0.32$ \\
Head width $(\mu \mathrm{m})$ & $4.26^{\mathrm{a}} \pm 0.19$ & $4.07^{\mathrm{b}} \pm 0.18$ \\
Head perimeter $(\mu \mathrm{m})$ & $23.39^{\mathrm{a}} \pm 0.98$ & $22.29^{\mathrm{b}} \pm 0.64$ \\
Head area $\left(\mu \mathrm{m}^{2}\right)$ & $27.79^{\mathrm{a}} \pm 1.17$ & $25.29^{\mathrm{b}} \pm 0.95$ \\
\hline
\end{tabular}

Different superscript letters designate significant differences between means within rows at $\mathrm{P} \leq 0.05$

Table 3. Sperm head morphology according to Tygerberg strict criteria in boar sperm

\begin{tabular}{lll}
\hline $\begin{array}{l}\text { Morphometric } \\
\text { parameter }\end{array}$ & $\begin{array}{l}\text { Sperm with normal } \\
\text { structure }\end{array}$ & $\begin{array}{l}\text { Sperm with Dag } \\
\text { defect }\end{array}$ \\
\hline Ellipticity & $1.95^{\mathrm{a}} \pm 0.13$ & $1.96^{\mathrm{a}} \pm 0.14$ \\
Elongation & $0.32^{\mathrm{a}} \pm 0.02$ & $0.32^{\mathrm{a}} \pm 0.03$ \\
Roughness & $0.63^{\mathrm{a}} \pm 0.04$ & $0.64^{\mathrm{b}} \pm 0.02$ \\
Regularity & $0.99^{\mathrm{a}} \pm 0.02$ & $1.01^{\mathrm{b}} \pm 0.03$ \\
\hline
\end{tabular}

Different superscript letters designate significant differences between means within rows at $\mathrm{P} \leq 0.05$

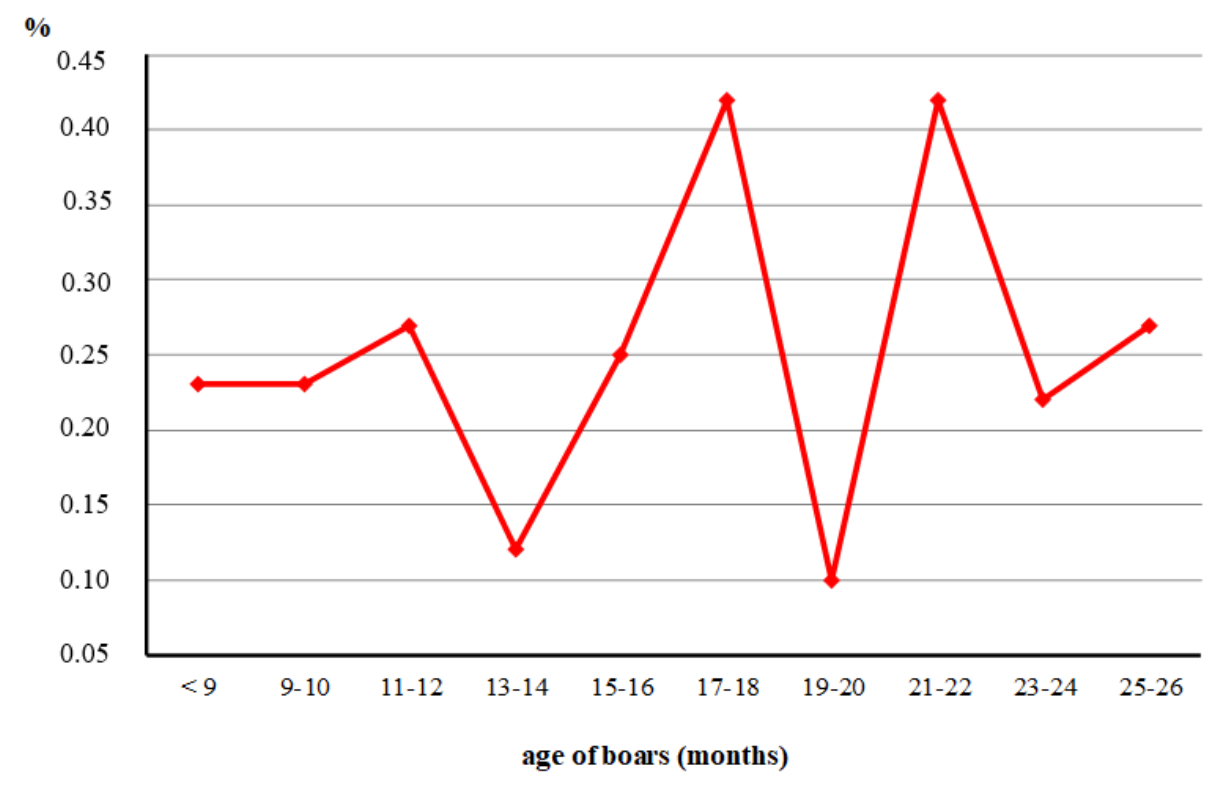

Fig. 2. Frequency of sperm with the Dag defect in Duroc boars by age

\section{Discussion}

According to Barth and Oko (5), Dag defect frequency of up to $4 \%$ may indicate testicular and epididymal dysfunction. When the percentage of this defect exceeds $50 \%$, it can have serious consequences involving reduced fertility (5). Research conducted on human material has shown a tendency for coiling sperm to occur in the semen of infertile men (43). However, according to the authors, sperm coiling was not dependent on sperm quantity or hormonal status, but may have been associated with qualitative semen characteristics, a hostile endogenous milieu, and an unknown suboptimal epididymal environment. While certain morphological defects occurring in greater quantities in sperm, such as distal cytoplasmic droplets, do not result in reduced fertility, other abnormalities (e.g. decapitated spermatozoa, the knobbed acrosome defect, nuclear vacuoles, short tails, the Dag defect, or corkscrewed midpieces) are considered serious defects that can impede fertilisation and cause infertility (35). Prochowska et al. (31) suggested that the Dag defect is not hereditary but caused by changes in osmotic pressure. Observations by Villaverde et al. (40) conducted using an electron microscope on the sperm of domestic cats indicate the presence of sperm defects similar to 
those described in other species as the Dag defect. The authors describe the sperm defects in detail as heavily coiled sperm tails containing several axonemal units enclosed in a common cell membrane, aberrations in the axonemal main structure, and swollen and unevenly distributed mitochondria in the midpiece. The authors also noted abnormalities of the mitochondrial sheath in spermatozoa from the testicles and epididymis of cats following castration (40). The sperm tail may also become bent or coiled due to abnormal epididymal secretion (42). According to Molnar et al. (28), structural changes take place in the epididymis and result in multiple fractures of the axonemal fibres and disruption of the mitochondrial sheath.

The Dag defect is associated with elevated zinc levels, disturbance in the testicles and/or epididymis, and fever (8). Boar sperm defects involving coiled tails were found to be caused during the passage of sperm from the distal caput to the proximal corpus epididymis, and there was a correlation between the onset of tailbending and the migration of the cytoplasmic droplet (20). Research by Zheng et al. (44) showed that proper cytoplasm removal is a genetically regulated process requiring the participation of the Spem1 gene. The lack of this gene impedes cytoplasm removal from the head and neck during the formation of the tail. Retention of a cytoplasmic droplet may impede the development of normal sperm and contribute to bending of the neck and wrapping of the midpiece and tail around the head, as observed in mice (29). Cytoplasmic droplet retention may result in bending of the tail, while the loss of the droplet allows the tail to remain straight, which facilitates the migration of sperm through the female reproductive tract (10). The presence of a cytoplasmic droplet on the midpiece can cause the tail to swell and fold (10), which prevents normal motility and reduces fertility (32). The presence of protoplasmic droplets may also indicate aberrations in the structure of the midpiece (36).

Thus far, studies on semen have shown that the morphology of sperm within one ejaculate is highly heterogeneous. Sperm differ in size and shape, while exhibiting normal morphological structure $(2,4,12)$. Research by Mandawala et al. (27) showed differences between the dimensions of sperm heads of fertile boars and those with limited fertility. The sperm heads of fertile boars have a larger area than in boars with lower fertility. Contrastingly, according to Hirai et al. (19) the sperm heads of highly fertile boars were less elongated and significantly smaller than those of less fertile boars. Mandawala et al. (27), who identified three categories of morphological sperm head in boars, suggested that a certain type may be predominant in semen from subfertile boars. Curry (11) also indicated that certain subtle differences in the shape of the sperm head may affect the fertility potential of the sperm. In contrast to the standard assessment, Tygerberg strict criteria define sperm head aberrations more rigorously (9). Particular findings for sperm morphology when additionally assessed according to Tygerberg strict criteria are a good biomarker of sufficient sperm dysfunction to result in infertility (38). This was confirmed by research by El-Ghobashy and West (13), which showed a positive correlation between human fertilisation rates and the percentage of sperm with normally shaped heads. Correct classification and quantification of a specific sperm structure defect may therefore provide valuable information on the potential fertility of the male and may help to make a diagnosis and prognosis of fertility problems (6).

The present study also attempts to analyse the occurrence of sperm with the Dag defect in boar semen by the age of the donor animal, because semen morphology and sperm shape and dimensions change through the reproductive life of the boar $(1,25,39)$. Studies by many authors indicate better reproductive results in older boars aged $19-30$ months $(14,24)$ or 30-36 months (22). The present authors (1) showed that as boars age, the percentage of sperm with abnormal morphological structure decreases. Semen collected from the youngest breeders (up to about nine months old) may contain many more sperm with morphological anomalies than the semen of more mature boars over the age of one year. Furthermore, in the semen of young Duroc boars under the age of nine months, the authors found that more than $5 \%$ of sperm had heads with major morphological defects, and that their frequency was determined by the high proportion of sperm with proximal protoplasmic droplets on the midpiece. There are studies indicating that the presence of cytoplasmic droplets on the sperm midpiece may be linked to chromatin instability (41) and abnormal sperm head dimensions (15), because the head, neck, midpiece and tail develop simultaneously during spermiogenesis (16). Banaszewska et al. (1) showed that in the semen of males from 9 months to 12 months of age, the share of sperm with primary defects gradually decreased, never exceeding $2.4 \%$. However, the authors observed that the semen of Duroc boars in this age range often contained sperm with secondary morphological defects (2.78-15.65\%), occurring at various rates in boars of different ages. The present study confirms that the semen of Duroc boars may have an elevated percentage of sperm with certain morphological defects including the Dag defect, which was found in the semen of boars of various ages. Research by Gloria et al. (17) shows that the Dag defect was less common $(0.9 \%)$ in the semen of boars 17-24 months of age than in that of mature bulls aged 4 to 7 years (1.4\%). Research by Tsakmakidis et al. (39) found a higher percentage of sperm with morphological defects, a higher percentage of sperm with chromatin instability, and sperm with longer heads in the ejaculates of young boars aged 7-10 months compared to boars described as mature at $18-33$ months. Boars of the Duroc breed, which were the subject of observation in this research, do not achieve $96 \%$ of sperm with normal morphology until the age of approximately 21 or 22 months (1). They also differ from boars of other breeds 
often used for artificial insemination in their relatively small ejaculate volume with a high sperm concentration (3), and all these distinctive features may be reflected in the quality, morphology and morphometry of the semen. Research by Iwanina and Kondracki (23) and Kondracki et al. (26) indicates that the incidence of sperm with the Dag defect in boar semen depends on both the sperm concentration in the ejaculate and the percentage of spermatozoa with progressive motility. Górski et al. (18) showed that the shape of the sperm head in boars of this breed correlates with the ejaculate volume, with more elongated sperm heads shown in ejaculates with a greater volume. Our research found differences in the head sizes of morphologically normal sperm and those with the Dag defect, the latter having smaller heads and a slightly different shape. This is well illustrated in Fig. 1, where even without analysing morphometric measurements the shapes of the post-acrosomal part of the head can be seen to be unalike, the shape being somewhat narrower in the case of sperm with the Dag defect. These are interesting observations worthy of further research, especially since other authors (15) have also confirmed differences in the head shapes and sizes of normal sperm and sperm with cytoplasmic droplets in boar semen, and since the relationship between morphometric dimensions and fertility which has been shown in many cases is still a subject of research.

Varying percentages of sperm with the Dag defect are found in the semen of Duroc boars. Given the origins of this defect and its likely genetic basis, as well as its fairly high frequency in the semen of males of various species, more in-depth analysis seems justified. Moreover, because differences in the head shapes of normal sperm and those with the Dag defect indicate the likelihood of changes not only where the defect was identified, i.e. the midpiece and tail, but also perhaps in the ultrastructure of the head and organisation of chromatin structure (condensation), these potential relationships should also be investigated in further research. In the case of boars intended for breeding, it is important to determine the reproductive performance of males before they join the breeding herd. Ascertainment of a boar's performance is important because although semen quality improves with the age of the boar, some individuals may have a predisposition to produce sperm with defects, which may result in a long-term reduction in fertilisation capacity or in the death of the embryo at earlier stages of development.

Conflict of Interests Statement: The authors declare that there is no conflict of interests regarding the publication of this article.

Financial Disclosure Statement: None requirement.

Animal Rights Statement: The authors declare that the experiments on animals were conducted in accordance with local Ethical Committee laws and regulations as regards the care and use of laboratory animals.

\section{References}

1. Banaszewska D., Andraszek K., Biesiada-Drzazga B.: Frequency of cytoplasmic droplets depends on the breed and age of insemination boars. Folia Biol (Krakow) 2015, 63, 9-18, doi: 10.3409/fb63_1.9.

2. Banaszewska D., Czubaszek M., Walczak-Jędrzejowska R., Andraszek K.: Morphometric dimensions of the stallion sperm head depending on the staining method used. Bull Vet Inst Pulawy 2015, 59, 263-270, doi: 10.1515/bvip-2015-0039.

3. Banaszewska D., Kondracki S.: An assessment of the breeding maturity of insemination boars based on ejaculate quality changes. Folia Biol (Krakow) 2012, 60, 151-162, doi: 10.3409/ fb60_34.151162.

4. Banaszewska D., Kondracki S., Wysokińska A.: Effect of age on the dimensions and shape of spermatozoa of Large White Polish boars. Arch Tierz 2011, 54, 504-514, doi: 10.5194/aab-54-5042011.

5. Barth A.D., Oko R.J.: Abnormal morphology of bovine spermatozoa, Iowa State Press, Ames, 1989, pp. 130-192.

6. Brito L.F.C., Greene L.M., Kelleman A., Knobbe M., Turner R.: Effect of method and clinician on stallion sperm morphology evaluation. Theriogenology 2011, 76, 745-750, doi: 10.1016/ j.theriogenology.2011.04.007.

7. Chenoweth P.J.: Genetic sperm defects. Theriogenology 2005, 64, 457-468, doi: 10.1016/j.theriogenology.2005.05.005.

8. Chenoweth P.J., McPherson F.J.: Genetic aspects of male reproduction. In: Animal andrology: theories and applications, edited by P.J. Chenoweth, S.P. Lorton, CABI, Wallingford, 2014, pp. 144-173, doi: 10.1111/avj.12431.

9. Coetzee K., Bermes N., Krause W., Menkveld R.: Comparison of normal sperm morphology outcomes from two different computer-assisted semen analysis systems. Andrologia 2001, 33, 159-163, doi: 10.1046/j.1439-0272.2001.00421.x

10. Cooper T.G.: The epididymis, cytoplasmic droplets and male fertility. Asian J Androl 2011, 13, 130-138, doi: 10.1038/ aja.2010.97.

11. Curry M.: Cryopreservation of semen from domestic livestock. Rev Reprod 2000, 5, 46-52, doi: 10.1530/ror.0.0050046.

12. Czubaszek M., Andraszek K., Banaszewska D., WalczakJędrzejowska R.: The effect of the staining technique on morphological and morphometric parameters of boar sperm. PLoS One 2019, 14, e0214243, doi: 10.1371/journal.pone.0214243.

13. El-Ghobashy A.A., West C.R.: The human sperm head: a key for successful fertilization. $\mathrm{J}$ Androl 2003, 24, 232-238, doi: 10.1002/j.1939-4640.2003.tb02667.x.

14. Fraser L., Strzeżek J., Filipowicz K., Mogielnicka-Brzozowska M., Zasiadczyk L.: Age and seasonal-dependent variations in the biochemical composition of boar semen. Theriogenology 2016, 86, 806-816, doi: 10.1016/j.theriogenology.2016.02.035.

15. Gaggini T.S., Rocha L.O., Souza E.T., Marcondes de Rezende F., Antunes R.C., Beletti M.E.: Head morphometry and chromatin instability in normal boar spermatozoa and in spermatozoa with cytoplasmic droplets. Anim Reprod 2017, 14, 1253-1258, doi: 10.21451/1984-3143-AR921.

16. Gil M.C., García-Herreros M., Aparicio I.M., Santos A.J., García-Marín L.J.: Morphometry of porcine spermatozoa and its functional significance in relation with the motility parameters in fresh semen. Theriogenology 2009, 71, 254-263, doi: 10.1016/j.theriogenology.2008.07.007.

17. Gloria A., Carluccio A., Wegner L., Robbe D., Valorz C., Contri A.: Pulse wave Doppler ultrasound of testicular arteries and their relationship with semen characteristics in healthy bulls. J Anim Sci Biotechnol 2018, 14, 1-7, doi: 10.1186/s40104-017-0229-6.

18. Górski K., Kondracki S., Wysokińska A.: Ejaculate traits and sperm morphology depending on ejaculate volume in Duroc boars. J Vet Res 2017, 61, 121-125, doi: 10.1515/jvetres-20170015.

19. Hirai M., Boersma A., Hoeflich A., Wolf E., Foll J., Aumüller T.R., Braun J.: Objectively measured sperm motility and sperm head 
morphometry in boars (Sus scrofa): relation to fertility and seminal plasma growth factors. J Androl 2001, 22, 104-110.

20. Holt W.V.: Epididymal origin of a coiled-tail sperm defect in a boar. J Reprod Fert 1982, 64, 485-489.

21. Hough S.R., Kaproth M.T., Foote R.H.: Incidence of the acrosome reaction and zona free hamster oocyte penetration by a bull with complete tetraspermia versus a halfbrother with normal sperm. J Androl 2002, 23, 98-106, doi: 10.1002/j.1939-4640.2002. tb02602.x.

22. Huang Yh., Lo Ll., Liu Sh., Yang T.S.: Age-related changes in semen quality characteristics and expectations of reproductive longevity in Duroc boars. Anim Sci 2010, 81, 432-437, doi: 10.1111/j.1740-0929.2010.00753.x.

23. Iwanina M., Kondracki S.: Dependence of the frequency of sperm defects and dimensions on sperm motility in ejaculates of Polish Landrace boars. Sci Ann Pol Soc Anim Prod 2019, 15, 33-45, doi: 10.5604/01.3001.0013.5067

24. Knecht D., Jankowska-Mąkosa A., Duziński K. The effect of age, interval collection and season on selected semen parameters and prediction of AI boars productivity. Livest Sci 2017, 201, 13-21, doi: 10.1016/j.livsci.2017.04.013.

25. Kondracki S., Banaszewska D., Mielnicka C.: The effect of age on the morphometric sperm traits of domestic pig (Sus scrofa domestica). Cell Mol Biol Lett 2005, 10, 3-13.

26. Kondracki S., Górski K., Iwanina M.: Impact of sperm concentration on sperm morphology of large white and landrace boars. Livest Sci 2020, 241, 1-10, doi: 10.1016/j.livsci.2020. 104214

27. Mandawala A.A., Skinner B.M., Walling G.A., Fowler K.E., Harvey S.C.: Sperm morphology differences associated with pig fertility. bioRxiv, 2018, doi: 10.1101/314708.

28. Molnar A., Sarlos P., Fancsi G., Ratky J., Nagy S., Kovacs A.: A sperm tail defect associated with infertility in a goat - case report. Acta Vet Hung 2001, 49, 341-348, doi: 10.1556/004.49.2001.3.11.

29. O’Connor R.E., Fonseka G., Frodsham R., Archibald A.L., Lawrie M., Walling G.A., Griffin D.K.: Isolation of subtelomeric sequences of porcine chromosomes for translocation screening reveals errors in the pig genome assembly. Anim Genet 2017, 48, 395-403, doi: 10.1111/age.12548.

30. Oettlé E.E.: Sperm abnormalities in the dog: a light and electron microscopic study. A thesis submitted to the Faculty of Medicine, University of Cape Town, in fulfilment of the requirements for the degree of Doctor of Philosophy. University of Cape Town, 1990, http://hdl.handle.net/11427/27179.

31. Prochowska S., Niżański W., Ochota M., Partyka A.: Characteristics of urethral and epididymal semen collected from domestic cats - a retrospective study of cases. Theriogenology 2015, 84, 1565-1571, doi: 10.1016/j.theriogenology.2015.08.005.

32. Rengan A.K., Agarwal A., Van Der Linde M., du Plessis S.S.: An investigation of excess residual cytoplasm in human spermatozoa and its distinction from the cytoplasmic droplet. Reprod Biol Endocrinol 2012, 10, 1-8, doi: 10.1186/1477-782710-92.

33. Ribeiro H.F.L., Vale W.G.: Dag defect in Murrah buffalo bulls in Brazil. Ital J Anim Sci 2007, 6, 667-670, doi: 10.4081/ijas.2007.s2.667.

34. Saacke R.G.: What is abnormal? And is abnormal dependent upon the animal? In: Proceedings of the $13^{\text {th }} N A A B$ Technical Conference on Artificial Insemination and Reproduction 1990, National Association of Animal Breeders, Madison, 1990, pp. 67-73.

35. Saravia F., Núñez-Martínez I., Morán J., Soler C., Muriel A., Rodríguez-Martínez H., Peña F.J.: Differences in boar sperm head shape and dimensions recorded by computer-assisted sperm morphometry are not related to chromatin integrity. Theriogenology 2007, 68, 196-203, doi: 10.1016/j.theriogenology. 2007.04.052.

36. Sławeta R., Morstin J.: Morphological changes in semen of boars of Polish White and Polish Great White breeds in various seasons of the year. Med Weter 1982, 410-413.

37. Sundararaman M.N., Gopinathan A., Subramanian A.: Dag-like sperm defect and acrosome abnormalities indicating hereditary sperm defects in a Jersey bull. Indian J Anim Reprod 2014, 35, 27-30.

38. Taşdemir I., Taşdemir M., Tavukçuoğlu S., Kahraman S., Biberoğlu K.: Effect of abnormal sperm head morphology on the outcome of intracytoplasmic sperm injection in humans. Hum Reprod 1997, 12, 1214-1217, doi: 10.1093/humrep/12.6.1214.

39. Tsakmakidis I.A., Khalifa T.A.A., Boscos C.M.: Age-related changes in quality and fertility of porcine semen. Biol Res 2012, 45, 381-386, doi: 10.1590/S0716-97602012000400009.

40. Villaverde A.I.S.B., Fioratti E.G., Ramos R.S., Neves R.C.F., Cardoso G.S., Landim-Alvarenga F.C., Lopes M.D.: High incidence of "Dag-like" sperm defect in the domestic cat. J Feline Med Surg 2013, 15, 317-322, doi: 10.1177/1098612X12469368.

41. Volker G.: Untersuchungen zur Verbesserung der In-vitroDiagnostik von Eberspermien und Ermittlung der Beziehung zum Befruchtungserfolg. Thesis, University of Veterinary Medicine Hannover, 2004.

42. Yeung C.H., Barfield J.P., Cooper T.G.: Physiological volume regulation by spermatozoa. Mol Cell Endocrinol 2006, 250, 98-105, doi: 10.1016/j.mce.2005.12.030.

43. Yeung C.H., Tüttelmann F., Bergmann M., Nordhoff V., Vorona E., Cooper T.G.: Coiled sperm from infertile patients: characteristics, associated factors and biological implication. Hum Reprod 2009, 24, 1288-1295, doi: 10.1093/humrep/dep017.

44. Zheng H., Stratton C.J., Morozumi K., Jin J., Yanagimachi R., Yan W.: Lack of Spem1 causes aberrant cytoplasm removal, sperm deformation, and male infertility. Proc Natl Acad Sci USA 2007, 104, 6852-6857, doi: 10.1073/pnas.0701669104 